\title{
Differences in Some Morphological Characteristics and Body Mass Index in Children of Younger School Age with Reference to Their Gender
}

\author{
Boris Banjevic ${ }^{1}$ \\ 'Army of Montenegro, Airforce military of Montenegro, Podgorica, Montenegro
}

\begin{abstract}
Kinesiologists have long ago noticed the great importance of determining and comparing parameters of growth and development in certain age of school children and youth. The aim of the research is to determine eventual existence of statistically significant differences in morphological characteristics and and body mass index with boys and girls of younger school age. The research has been performed on a sample of 60 students divided into two groups: 32 boys and 28 girls from the second and and third grade of the Primary school "Jagos Kontic" from Nikšić. Morphological characteristics were evaluated by a battery of four variables: body height, body weight, waist circumference and hip circumference. The values of the body mass index have been calculated. The significance of the differences between gender was determinated by t-test for small independent samples. Significant differences have been established in the body height and waist circumference in favour of boys. The obtained data about nourishment based on the body mass index (BMI) indicate a high percentage of normal nutritional status for the complete sample of the examinees. The obtained results of research confirm the need to perform a more comprehensive research of morphological indicators in this age.
\end{abstract}

Key words: Morphological Characteristics, Body Mass Index, Younger School Age

\section{Uvod}

Procesi rasta i razvoja dece su u interakciji, pa je neophodno poznavati ne samo kvantitativne nivoe, nego i prirodu relacija morfološkog i funkcionalnog sazrevanja dece, kako u određenom uzrastu, tako i po polu (Bala, 2009; Bjelica i Petković, 2009). Redovno praćenje telesnog rasta i razvoja, počevši od dijagnostičke evaluacije (inicijalnog praćenja), doprinosi detekciji abnormalnosti rasta i razvoja, ranoj identifikaciji gojaznosti i pothranjenosti (NCD Risk Factor Collaboration, 2019). Ona omogućava individualniji pristup učenicima i kvalitetnije programiranje nastave fizičkog vaspitanja (Smajić i sar., 2017).

Definisati zdravlje samo u smislu odsustva bolesti, potpuno je pogubno i neodgovorno (Bjelica i Krivokapić, 2010). Jedna od glavnih komponenti pravilnog tjelesnog sazrijevanja djeteta je stvaranje uslova za pravilan rast i razvoj, što će doprinijeti skladnom psiho-fizičkom dignitetu svake jedinke ponaosob (Bjelica, 2006). U današnjem vremenu je prisutan sve veći broj remetilačkih faktora pravilnog tjelesnog sazrijevanja kod djece mlađeg školskog uzrasta (Lovric, Mandic Jelaska, \& Bilic, 2018). U prilog takvoj konstataciji stoji i činjenica da se upravo radi o jednom od kritičnih perioda za nastanak negativnih posturalnih promjena, što je svakako uzročno-posljedično vezano sa parametrima rasta i razvoja.

Utvrđivanje stanja uhranjenosti bi trebalo, zbog same jednostavnosti primene i upotrebljivosti rezultata, češće realizovati u smislu prevencije i predupređivanja određenih stanja. U ekspanziji su problematični socijalni uslovi kao posledica masovne urbanizacije i uticaja zapadne kulture $\mathrm{u}$ svim oblastima života, a naročito među školskom djecom

\section{Correspondence:}

Montenegro Gport 
koja su hipersenzibilna na svjetske trendove. Ovi pomenuti trendovi su integralni deo "nutritivne tranzicije", koja, udružena sa sedentarnim načinom života (deficit fizičke aktivnosti), nosi multiple rizike po zdravlje. Na taj način, pojam zdravlja gubi smisao, jer mladost i odsustvo bolesti više nisu sinhroni indikatori kvaliteta života (Gligorijević, 2008).

U novije vrijeme se nekoliko studija bavilo sagledavanjem rasta i razvoja djece mlađeg školskog uzrasta (Božić-Krstić, Rakić i Pavlica, 2003; Bigović, 2004; Bigović, Obradović i Krsmanović, 2007; Gligorijević, 2008; Stojanović i Zrnzević, 2010; Vasić i sar., 2011, B. Krsmanović, Batez i T. Krsmanović, 2011; Vasiljević, Vukičević i Stoisavljević, 2015; Ješić, 2017; Smajić i sar., 2017). U ovim studijama se osim utvrđivanja nivoa morfoloških pokazatelja, vršilo i njihovo upoređivanje u odnosu na pol.

Morfološke karakteristike dece mlađeg školskog doba vrlo su značajne za realizaciju motoričkih struktura u kojima one predstavljaju realnu biomehaničku osnovu, kako kao faktori koji olakšavaju, tako i kao faktori koji otežavaju izvođenje motornih zadataka (Smajić i sar., 2017; Arifi, Bjelica, \& Masanovic, 2019). U skladu sa tom činjeničnom postavkom koja ukazuje na izuzetan značaj praćenja parametara rasta i razvoja i interesovanjem autora rada, definisan je predmet ovog istraživanja, koji se odnosi na uži prostor morfoloških pokazatelja u čijoj strukturi su jedan parametar longitudinalne dimenzionalnosti i tri parametra mase i volumena tijela.

S obzirom da se radi o uzrasnoj dobi ujednačenog razvoja psihosomatskog statusa u odnosu na pol, a imajući u vidu rezultate pojedinih studija koji ukazuju da u pojedinim slučajevima ipak dolazi do izvjesne polne diferencijacije u smislu postojanja morfoloških razlika, postavljen je cilj istraživanja. On podrazumijeva definisanje eventualnih razlika u morfološkim karakteristikama i uhranjenosti kod dječaka i djevojčica mlađeg školskog uzrasta, na osnovu antropometrijskih mjera i indeksa tjelesne mase (BMI). Zapravo, žele se provjeriti tvrdnje prethodnih studija (Bigović, 2004; Zrnzević, 2006; Gligorijević, 2008; B. Krsmanović, Batez i T. Krsmanović, 2011) u kojima je utvrđeno postojanje rodnih razlika kada su u pitanju pojedine morfološke karakteristike djece mlađeg školskog uzrasta. U ostvarivanju cilja postavljeni su sljedeći zadaci: utvrditi nivo morfoloških karakteristika učenika, utvrditi nivo morfoloških karakteristika učenica, utvrditi nivo uhranjenosti na osnovu izračunavanja indeksa tjelesne mase (BMI) i utvrditi razlike u morfološkim karakteristikama između učenika i učenica.

\section{Metod}

U radu je korišćen eksperimentalni metod, a za prikupljanje podataka antropometrijska mjerenja po metodi Inrernacionalnog biološkog programa (IBP).
Uzorak ispitanika sačinjavali su učenici i učenice drugih i trećih razreda OŠ "Jagoš Kontić” iz Nikšića. Prosjek godina starosti ispitivanog uzorka je osam. Uzorak je podijeljen na dva subuzorka, i to: subuzorak od 32 učenika i subuzorak od 28 učenica. Učenici su dobrovoljno i uz saglasnost roditelja učestvovali u istraživačkom postupku i redovno su pohađali nastavu fizičkog vaspitanja.

Mjerenje je sprovedeno u fiskulturnoj sali OŠ "Jagoš Kontić”, a djeca su bila odjevena u sportskoj opremi predviđenoj za realizaciju časa fizičkog vaspitanja.

Uzorak mjera su činili sljedeći morfološki pokazatelji: ATV-tjelesna visina, ATT-tjelesna težina, AOS-obim struka i AOK-obim kukova. Tjelesna visina je mjerena antropometrom. Ispitanici su stajali bosi na ravnoj podlozi, u uspravnom stavu, relaksiranih ramena i sastavljenih peta. Glava im je bila namještena tako da je frankfurtska horizontala bila u vodoravnom položaju. Tjelesna težina je mjerena medicinskom vagom, pri čemu su ispitanici stajali bosi na njoj, mirno i u uspravnom stavu. Obim struka i obim kukova su mjereni neelastičnom santimetarskom trakom, za prvu mjeru na sredini rastojanja karličnog vrha i grudnog koša, odnosno, za drugu mjeru iznad linije koja razdvaja butinu od sedalne regije na tački gdje je maksimalan obim preko stražnjeg dijela. Za procjenu uhranjenosti izračunat je BMI-indeks tjelesne mase.

Dobijeni rezultati su najprije uređeni, a zatim statistički obrađeni na personalnom računaru pomoću statističkog paketa SPSS 17.0. Izračunati su centralni i disperzioni parametri varijabli, a za utvrđivanje razlika u antropometrijskim karakteristikama, primijenjen je t-test za nezavisne uzorke. Body mass index (BMI) je metoda indeksa korišćena kao dopunska metoda za ocjenjivanje stanja uhranjenosti ispitanika, pri čemu je klasifikacija istih izvršena prema prihvaćenim vrijednostima prekomjerne uhranjenosti i gojaznosti za djecu i adolescente (Vasić i sar., 2011; Cole, 2000), a koje su u skladu sa preporukama evropskog Centra za prevenciju i kontrolu bolesti.

\section{Rezultati}

U tabelama 1 i 2 prikazani su osnovni statistički deskriptivni parametri morfoloških varijabli za subuzorke učenika i učenica, gdje su izračunate mjere centralne i disperzione tendencije i to: aritmetička sredina (Mean), standardna devijacija (S.D.), varijansa (Variance), minimalne (Min) i maksimalne (Max) vrijednosti, koeficijenti nagnutosti (Skewness) i zakrivljenosti (Kurtosis).

Prema vrijednostima skjunisa koje imaju pozitivan predznak za sve varijable, uviđa se pozitivna asimetrija sa dominacijom slabijih rezultata, dok pozitivna vrijednost kurtozisa kod svih varijabli ukazuje na leptokurtičnost koju karakteriše izrazita homogenost rezultata (Tabela 1 ).

Tabela 1. Centralni i disperzioni parametri antropometrijskih varijabli učenika

\begin{tabular}{|c|c|c|c|c|c|c|c|c|c|}
\hline \multirow{2}{*}{ Variable } & \multirow{2}{*}{ Min } & \multirow{2}{*}{ Max } & \multirow{2}{*}{ Mean } & \multirow{2}{*}{ S.D. } & \multirow{2}{*}{ Variance } & \multicolumn{2}{|c|}{ Skewness } & \multicolumn{2}{|c|}{ Kurtosis } \\
\hline & & & & & & Stat. & S.E. & Stat. & S.E. \\
\hline AVT & 117.5 & 148.7 & 133.4 & 6.91 & 47.75 & .063 & .414 & .117 & .809 \\
\hline ATT & 22.0 & 54.2 & 29.3 & 6.68 & 44.70 & 1.99 & .414 & 5.25 & .809 \\
\hline AOS & 50.0 & 89.8 & 61.3 & 8.89 & 79.13 & 1.77 & .414 & 3.13 & .809 \\
\hline AOK & 54.1 & 88.0 & 61.9 & 7.20 & 51.97 & 2.07 & .414 & 4.87 & .809 \\
\hline BMI & 13.4 & 26.4 & 16.2 & 2.67 & 7.14 & 2.43 & .414 & 6.62 & .809 \\
\hline
\end{tabular}

Legenda: Min. - minimalan rezultat; Max. - maksimalan rezultat; Mean - aritmetička sredina; SD -standarda devijacija; Variance - varijansa; Skwness - Mjera asimetrije; Kurtosis - Mjera spljoštenosti. 
$\mathrm{Na}$ osnovu pozitivnih vrijednosti skjunisa, kao i kod subuzorka učenika, zapaža se pozitivna asimetrija sa dominacijom slabijih rezultata. Negativna vrijednost kurtozisa za varijablu visina tijela (AVT) ukazuje na platikurtičnost i heterogenost rezultata. Kod ostalih varijabli se na osnovu pozitivnih vrijednosti kurtozisa zapaža homogenost, koja je naročito izražena za varijablu indeks tjelesne mase (Tabela 2).

Tabela 2. Centralni i disperzioni parametri antropometrijskih varijabli učenica

\begin{tabular}{|c|c|c|c|c|c|c|c|c|c|}
\hline \multirow{2}{*}{ Variable } & \multirow{2}{*}{ Min } & \multirow{2}{*}{ Max } & \multirow{2}{*}{ Mean } & \multirow{2}{*}{ S.D. } & \multirow{2}{*}{ Variance } & \multicolumn{2}{|c|}{ Skewness } & \multicolumn{2}{|c|}{ Kurtosis } \\
\hline & & & & & & Stat. & S.E. & Stat. & S.E. \\
\hline AVT & 117.6 & 143.7 & 130.1 & 6.48 & 42.11 & .061 & .441 & -.29 & .858 \\
\hline ATT & 20.3 & 44.9 & 26.8 & 5.74 & 32.98 & 1.50 & .441 & 2.39 & .858 \\
\hline AOS & 50.6 & 73.8 & 57.1 & 6.12 & 37.55 & 1.24 & .441 & 1.11 & .858 \\
\hline AOK & 51.2 & 75.8 & 59.1 & 6.11 & 37.37 & .95 & .441 & .67 & .858 \\
\hline BMI & 13.6 & 24.5 & 15.6 & 2.36 & 5.61 & 2.34 & .441 & 6.43 & .858 \\
\hline
\end{tabular}

Na osnovu dobijenih vrijednosti za indeks tjelesne mase $\quad \mathrm{ka}(27$ dječaka-84,38\% i 23 djevojčice-82,14\%) skoncentrisan (Tabela 3), uviđa se da je najveći broj ispitanika oba subuzor- u kategoriji normalna uhranjenost.

Tabela 3. Nivo uhranjenosti za učenike i učenice mlađeg školskog uzrasta

\begin{tabular}{ccccc}
\hline Uzorak & $\begin{array}{c}\text { Pothranjenost } \\
<\mathbf{5}\end{array}$ & $\begin{array}{c}\text { Normalna } \\
\text { uhranjenost } \\
\mathbf{5 - 8 5}\end{array}$ & $\begin{array}{c}\text { Prekomjerna } \\
\text { težina } \\
\mathbf{8 5 - 9 5}\end{array}$ & $\begin{array}{c}\text { Gojaznost } \\
>\mathbf{9 5}\end{array}$ \\
\hline Učenici & $1(3.12 \%)$ & $27(84,38 \%)$ & $3(9.37 \%)$ & $1(3.12 \%)$ \\
Učenice & $1(3,57 \%)$ & $23(82,14 \%)$ & $3(10.71 \%)$ & $1(3.57 \%)$ \\
Zbirno & $2(3 \%)$ & $50(83 \%)$ & $6(10 \%)$ & $2(3 \%)$ \\
\hline
\end{tabular}

Prema dobijenim rezultatima T-testa i osnovne statistike (AOS), u korist ispitanika muškog pola. U ostalim varijablama za definisane subuzorke (Tabela 4), konstatovane su statistički značajne razlike u varijablama visina tijela (AVT) i obim struka značajna razlika nije pronađena.

Tabela 4. Vrijednosti t-testa između aritmetičkih sredina varijabli za procjenu morfoloških karakteristika i indeksa tjelesne mase (BMI) učenika i učenica mlađeg školskog uzrasta

\begin{tabular}{ccccccc}
\hline Variable & $\mathbf{F}$ & $\mathbf{t}$ & $\mathbf{d f}$ & Sig. & Mean D. & S.E.D. \\
\hline AVT & .007 & 1.96 & 58 & .054 & 34.11 & 17.34 \\
ATT & .128 & 1.54 & 58 & .129 & 2.49 & 1.62 \\
AOS & 1.360 & 2.07 & 58 & .043 & 41.48 & 20.00 \\
AOK & .016 & 1.62 & 58 & .109 & 28.27 & 17.39 \\
BMI & .014 & .92 & 58 & .358 & .60 & .61 \\
\hline
\end{tabular}

Legenda: F - F vrijednost; Sig. - signifikantnost; t - t vrijednost; df - stepeni slobode; Mean D. - razlike aritmetičkih sredina; S.E.D. - standardna greška razlike.

\section{Diskusija}

Stav Svjetske zdravstvene organizacije je da u smislu adekvatnog praćenja akceleracije rasta i razvoja, treba primjenjivati komparacije sa definisanim nacionalnim standardima za određeni uzrast, kako bi se anuliralo dejstvo mnogobrojnih etnografskih razlika. Dobijeni rezultati u ovoj studiji su upoređivani sa rezultatima sličnih istraživanja iz okruženja i dostupnih standarda za pojedine parametre.

$\mathrm{Na}$ osnovu prikazanih rezultata deskriptivnih statističkih pokazatelja za subuzorak učenika, uviđa se da je prosječna vrijednost visine tijela $133,4 \mathrm{~cm}$. Zrnzević (2006) je dobila prosječnu visinu za učenike istog uzrasta $134,9 \mathrm{~cm}$, a rezultati i ostalih studija iz okruženja pokazuju razliku u odnosu na prosječnu visinu učenika u ovoj studiji, međutim ista nije na nivou statističke značajnosti. Na osnovu podataka Nacionalnog centra za zdravstvenu statistiku (Hejvud i Gečel, 2017), za navedeni uzrast se konstatuje raspon vrijednosti tjelesne visine 117-138 $\mathrm{cm}$. Zanimljivo je istaći da se minimalne vrijednosti visine tijela ispitanika obuhvaćenih njihovom studijom, gotovo podudaraju sa minimalnom visinom ispitanika obuhvaćenih ovom studi- jom $(117,5 \mathrm{~cm})$, dok maksimalne vrijednosti visine tijela učenika obuhvaćenih ovom studijom $(148,7 \mathrm{~cm})$ premašuju gornju granicu visine tijela ispitanika njihove studije. Napredovanje fenomena akceleracije u tjelesnoj visini djece mlađeg školskog uzrasta, može se utvrditi poređenjem rezultata ovog istraživanja sa Normativima antropometrijskih mjera djece i omladine u SFRJ iz 1962. godine (Medved, 1979). Naime, prosječna vrijednost za visinu učenika od osam godina iznosila je 125,7 cm, što je 7,7 cm manje od dobijenih vrijednosti u ovoj studiji. Ova razlika je u potpunosti u saglasju sa konstatacijom antropologa, da je prethodni vijek donio bitno ubrzanje rasta u populaciji industrijski razvijenih zemalja-prosjek 1-1,2 cm za jednu deceniju. Kada je u pitanju tjelesna visina učenica, prosječna vrijednost za visinu tijela je $130,1 \mathrm{~cm}$, što je niža vrijednost od rezultata pojedinih studija iz Srbije i Bosne i Hercegovine, koje pokazuju veće vrijednosti od navedene $2-4 \mathrm{~cm}$ (Stojanović i Zrnzević, 2010; Vasić i sar., 2011; Gligorijević, 2008). Prateći pojavu višedecenijske akceleracije tjelesne visine $u$ odnosu na utvrđene normative iz 1962. godine (Medved, 1979), konstatuje se da je njen prirast kod učenica ove studije $5,22 \mathrm{~cm}$. 
Prosječna tjelesna težina učenika je $29,3 \mathrm{~kg}$ što je manje za 1-4 kg u odnosu na rezultate pojedinih studija iz Srbije (Gligorijević, 2008; Ješić, 2017). Upoređujući srednje vrijednosti u odnosu na pokazatelje iz 1962. godine (Medved, 1979), zaključuje se prirast tjelesne težine učenika za $3,86 \mathrm{~kg}$. Sa druge strane, prosječna vrijednost težine tijela učenica obuhvaćenih ovom studijom iznosi $26,8 \mathrm{~kg}$, što je za 2-4 kg manje u odnosu na rezultate sličnih istraživanja iz okruženja (Vasić i sar., 2011; Ješić, 2017). U smislu praćenja akceleracije ovog morfološkog parametra, a na osnovu komparacije sa pokazateljima iz 1962. godine (Medved, 1979), zaključuje se prirast kod učenica ove studije za $2,12 \mathrm{~kg}$.

Dobijeni rezultati za morfološke pokazatelje obim struka i obim kukova su upoređeni sa vrijednostima dobijenim $u$ studiji antropometrijske analize učenika u ruralnom području (Vasić i sar., 2011). Srednje vrijednosti za obim struka su kod učenika veće za $1,3 \mathrm{~cm}$, a kod učenica manje za $3,2 \mathrm{~cm}$ $\mathrm{u}$ odnosu na pomenutu studiju. Za obim kukova kod učenika se uviđa niža prosječna vrijednost za $2,1 \mathrm{~cm}$, dok je kod učenica ova razlika znatno izraženija i iznosi $3,5 \mathrm{~cm}$. I pored izvjesnih sličnosti ruralnog i prigradskog područja, ovdje su se ipak javile evidentne razlike, koje se svakako moraju pripisati kompleksu dejstva raznovrsnih faktora i specifika genotipskih i fenotipskih modaliteta karakterističnih za različita etnografska područja.

Primjenom T-testa, utvrđeno je da između subuzoraka ispitanika postoji statistički značajna razlika u varijablama tjelesna visina i obim kukova. Slične rezultate za tjelesnu visinu dobila je i Gligorijević (2008). Međutim, treba istaći da se u najvećem broju ranijih istraživanja za ovaj uzrasni period nije potvrdila rodna polarizovanost za tjelesnu visinu (Stojanović i Zrnzević, 2010; Vasić i sar., 2011, B. Krsmanović, Batez i T. Krsmanivić, 2011; Smajić i sar., 2017). Kada se govori o razlici u obimu kukova, ona iznosi 2,8 cm u korist učenika. Kod ranije navedene studije (Vasić i sar., 2011), pomenuta razlika između polova je veća i iznosi $5 \mathrm{~cm}$ u korist ispitanika ženskog pola. Dakle, i pored harmonične akceleracije u ovom uzrasnom periodu, moguće je da usljed dejstva određenih faktora ipak dođe do razlika u pojedinim morfološkim parametrima između polova. Ovdje se osim genotipskih, kulturoloških, socio-psiholoških i mikrosocijalnih faktora, takođe mogu pomenuti i fiziološke promjene $u$ organizmu vezane za intenzivan period rasta i sazrijevanja koji će uslijediti. Može se konstatovati, da se u ovom uzrasnom periodu određene promjene ipak dešavaju, čime se potvrđuje činjenica da trend rasta pojedinih organa nije linearan, već da usljed dejstva brojnih, već pomenutuh faktora, ipak dolazi do izvjesnih odstupanja.

Dobijeni rezultati po pitanju uhranjenosti ukazuju da u oba subuzorka ispitanika skoro identično dominiraju djeca sa normalnom uhranjenosti (učenici-84,38\%, učenice-82,14\%). Obzirom na veličinu subuzoraka i ukupnog uzorka ispitanika, svakako se ne smiju zanemariti ni numeričke vrijednosti koje ukazuju na zastupljenost djece sa prekomjernom tjelesnom težinom i gojaznosti, koje su u potpunosti identične za pomenute kategorije (učenici-3,12\%, učenice-3.57\%). Upoređivanjem srednjih vrijednosti dobijenih rezultata indeksa tjelesne mase (BMI) sa drugim studijama koje su tretirale parametar uhranjenosti, vidljiva je podudarnost. Razlike su male za ispitivani uzrast i kreću se u intervalu $+1,-0,5 \mathrm{u}$ odnosu na rezultate za oba pola. Procenat prekomjerne tjelesne težine za ukupni uzorak ispitanika ove studije je 10\%, a gojaznosti $3 \%$. Upoređujući te vrijednosti sa rezultatima slične studije (Ješić, 2017), u čijem uzorku je prekomjerna tjelesna težina zastupljena sa $17,1 \%$, a gojaznost sa $7,1 \%$, konstatuje se znatno niži procenat ispitanika ove studije sa prekomjernom tjelesnom težinom i gojaznosti. Obzirom da se radilo $u$ uzorku ispitanika zdrave djece iz prigradskog naselja, koja su redovno pohađala nastavu fizičkog vaspitanja, zaključuje se da optimalno stanje pokazatelja zdravstvenog statusa u sadejstvu sa adekvatnom fizičkom aktivnošću ima esencijalnu važnost za balansiran razvoj parametara tjelesne kompozicije.

U skladu sa dobijenim rezultatima, moguće je izvesti zaključak da su ustanovljene razlike između polova na osnovu tjelesne visine i obima struka i pored činjenice da se radi o uzrasnom periodu harmonije i proporcionalnosti razvoja unutrašnjih organa i njihovih funkcionalnih sposobnosti sa razvojem morfoloških karakteristika. Rezultati ovog istraživanja nude doprinos u pravcu davanja smjernica nastavnicima fizičkog vaspitanja za provođenjem češćih mjerenja pojedinih pokazatelja antroplološkog statusa djece, obzirom na pristupačnost uzimanja navedenih podataka. Na taj način, obezbijediće se monitoring nastavnog procesa i preduprijeđivanje nastajanja i trenda napredovanja u razvoju negativnih pojava gojaznosti i posturalnih poremećaja. Obzirom na veličinu ispitivanog uzorka, uži sistem obuhvaćenih morfoloških varijabli, kao i dejstvo raznovrsnih faktora na proces rasta i razvoja, nije moguće donijeti dodatne zaključke, koji bi bili u skladu sa statističkom i kineziološkom zakonomjernošću. Ipak, to ne umanjuje vrijednost ove studije, koja je zapravo ukazala na veliki značaj praćenja pojedinih parametara rasta i razvoja kod djece mlađeg školskog uzrasta.

\section{Acknowledgements}

There are no acknowledgements.

\section{Conflict of Interest}

The authors declare that there are no conflicts of interest.

Received: 1 May 2019| |Accepted: 3 June 2019| Published: 4 July 2019

\section{References}

Arifi, F., Bjelica, D., \& Masanovic, B. (2019). Differences in anthropometric characteristics among junior soccer and handball players. Sport Mont, 17(1), 45-49. doi: 10.26773/smj.190208

Bala, G. (2009). Relacije antropoloških karakteristika isposobnostipredškolske dece. Novi Sad: Fakultet sporta i fizičkog vaspitanja.

Bigović, M. (2004). Efikasnost nastave fizičkog vaspitanja u odnosu na stručnu osposobljenost nastavnika. Neobjavljena magistarska teza. Novi Sad: Fakultet sporta i fizičkog vaspitanja.

Bigović, M., Obradović, J., \& Krsmanović, T. (2007). Rast i razvoj učenica nižih razreda osnovne škole. Glasnik Antropološkog društva Jugoslavije, 42, 345-351.

Bjelica, D. (2006). Teorijske osnove tjelesnog i zdrastvenog obrazovanja. Podgorica: Crnogorska sportska akademija.

Bjelica, D., i Krivokapić, D. (2010). Teorijske osnove fizičke kulture. Nikšić: Fakultet za sport i fizičko vaspitanje Univerziteta Crne Gore.

Bjelica, D., i Petković, J. (2009). Teorija fizičkog vaspitanja i osnove školskog sporta. Podgorica: Univerzitet Crne Gore.

Božić-Krstić, V., Rakić, R., \& Pavlica, T. (2003). Telesna visina i masa predškolske i mlađe školske dece u Novom Sadu. Glasnik Antropološkog društva Jugoslavije, 38, 91-100.

Gligorijević, S. (2008). Antropometrijski parametri kao pokazatelji akceleracije rasta i prediktori gojaznosti predadolescenata. Acta Medica Medianae, 47(2), 15-19.

Hejvud, K., \& Gečel, N. (2017). Motorički razvoj kroz život. Podgorica: Univerzitet Crne Gore.

Ješić, M. (2017). Prediktori gojaznosti učenika mlađeg školskog uzrasta. Neobjavljena magistarska teza. Beograd: Fakultet sporta i fizičkog vaspitanja.

Krsmanović, B., Batez, M., \& Krsmanović, T. (2011). Razlike u antropometrijskim karakteristikama i unhranjenosti kod dečaka i devojčica. Glasnik Antropološkog društva Srbije, 46, 89-94. 
Lovric, F., Mandic Jelaska, P., \& Bilic, Z. (2018). Physical activity cannot be treated as a predictor of anthropological status among six-year-old children. Montenegrin Journal of Sports Science and Medicine, 7(1), 53-57. doi: 10.26773/ mjssm. 180307

Medved, R. (1979). Sportska medicina. Zagreb: Jugoslovenska medicinska knjiga. NCD Risk Factor Collaboration (2019). Rising rural body-mass index is the main driver of the global obesity epidemic in adults. Nature, 569, 260-264. doi: 10.1038/s41586-019-1171-x

Smajić, M., Marinković, A., Đorđić, V., Čokorilo, N., Gušić, M., \& Štajer, V. (2017). Razlike u morfološkim karakteristikama i motoričkim sposobnostima devojčica i dečaka mlađeg školskog utrasta. Glasnik Antropološkog društva Srbije, 52, 89-93.
Stojanović, J., \& Zrnzević, N. (2010). Stanje uhranjenosti dece mlađeg školskog uzrasta. Sport Mont, 8(23-24), 226-234.

Vasić, Z., Vidović, S., Šuščević D., Karan, Ž., Lončar, M., Ramić, I., \& Dragić S. (2011). Antropometrijska analiza učenika osnovne škole u ruralnom području. Glasnik Antropološkog društva Srbije, 46, 95-102.

Vasiljević, D., Vukičević, T., \& Stoisavljević, M. (2015). Stanje uhranjenosti učenika mlađeg školskog uzrasta. Zbornik radova Učiteljskog fakulteta, 9, 237-245.

Zrnzević, N. (2006). Razlike u morfološkim karakteristikama i motoričkim sposobnostima učenika i učenica drugog razreda osnovne škole. Sport Mont, 4(10-11), 488-494. 